\title{
A Delay Discounting Measure of Great Expectations and the Effectiveness of Psychotherapy
}

\author{
Joshua K. Swift \\ Oklahoma State University
}

\author{
Jennifer L. Callahan \\ University of North Texas
}

\begin{abstract}
Many clients prematurely terminate therapy before they have recovered. One possible explanation for treatment dropout is unmet expectations. Although the effects of unmet role expectations have received much attention in the literature, little is known about unmet outcome expectations. Two studies were designed to look at duration and effectiveness outcome expectations held by individuals within a primary referral base for a training clinic setting - a setting with a slower rate of recovery than other outpatient settings. Study $1(N=110)$ used a delay discounting method to find rate-of-recovery expectations associated with differing treatment lengths. Results indicated expectations much higher than the demonstrated effectiveness of therapy associated with training clinics. Study $2(N=307)$ replicated Study 1 and examined the possibility of altering outcome expectations through education. Study 2 results indicated that outcome expectations may be altered through client education. Both studies' results are discussed in terms of reducing premature termination and overall treatment outcome.
\end{abstract}

Keywords: psychotherapy, expectancies, expectations, training, premature termination

Premature termination or treatment dropout is a major problem seen in the practice of psychotherapy (Garfield, 1994; Reis \& Brown, 2006). A number of studies indicate that approximately $30 \%$ of clients attend only an intake session, with the average client attending somewhere between three and five sessions (Garfield, 1994; N. B. Hansen, Lambert, \& Forman, 2002). Further, a large number of clients, generally reported as between $40 \%$ and $60 \%$, terminate therapy before they have seen any reliable benefits (Callahan \& Hynan, 2005; Clarkin \& Levy, 2003; Garfield, 1994; Wierzbicki \& Pekarik, 1993). Although many different variables may be related to premature termination, it has been suggested that unmet client expectations may play a large role (Garfield, 1994; Wierzbicki \& Pekarik, 1993).

When looking at unmet expectations, it is important to distinguish between two types: role expectations and outcome expectations (Dew \& Bickman, 2005). Role expectations refer to the behaviors that a client expects in the therapy situation (e.g., who will do most of the talking, will there be homework assigned, etc.), and a large body of literature indicates that disconfirmation of these types of expectations is related to premature termination (e.g., Hardin, Subich, \& Holvey, 1988; Nock \& Kazdin, 2001; Reis

JoshuA K. SWIFT is a doctoral candidate in the clinical psychology program at Oklahoma State University. His research interests include psychotherapy processes and outcomes with a specific focus on examining the client's role in treatment.

JenNifer L. CALLAhAn received her PhD in clinical psychology from the University of Wisconsin-Milwaukee. She is an assistant professor in psychology at the University of North Texas and holds board certification in clinical psychology. Her research interests span the assessment and psychotherapy domains, with an emphasis on competency development in these areas.

CORRESPONDENCE CONCERNING THIS ARTICLE should be addressed to Jennifer L. Callahan, Department of Psychology, University of North Texas, P.O. Box 311280, Denton, TX 76203-1280. E-mail: jennifercallahan@unt.edu
\& Brown, 1999; Walitzer, Dermen, \& Conners, 1999). On the other hand, outcome expectations refer to the effectiveness that a client expects from psychotherapy and may include things like expected likelihood of improvement, expected level of symptom reduction, expected length of therapy, or expected length of time needed before improvement is seen (Garfield, 1994). A number of studies have found a relationship between disconfirmation of outcome expectations and premature termination (Garcia \& Weisz, 2002; A. M. Hansen, Hoogduin, Schaap, \& de Haan, 1992).

Attempts have been made to measure outcome expectations for psychotherapy. Pekarik and Wierzbicki (1986) examined the expected duration of treatment for 148 outpatient clients. When asked how many visits they thought they would attend, $20.3 \%$ of clients expected $1-2$ sessions, $28.4 \%$ expected $3-5$ sessions, and $24.3 \%$ expected $6-10$ sessions. Similar results have been found in more recent studies for clients seeking services across treatment orientations, disorders, and settings (Mueller \& Pekarik, 2000; Pekarik, 1991; Wierzbicki \& Pekarik, 1993).

Previous studies assessing expected treatment duration or outcome expectations have all used similar methods: directly asking clients to indicate the number of sessions they think they will attend. However, when considering treatment duration, clients' expectations may also be influenced by how effective the treatment is perceived to be. To date, no studies have examined treatment duration expectations in view of expectations concerning treatment effectiveness (e.g., rate of recovery).

A delay discounting method is one way to examine treatment duration expectations in view of expectations concerning treatment effectiveness. Delay discounting refers to a preference between two rewards: a smaller immediate reward and a larger delayed reward (Critchfield \& Kollins, 2001). Although delay discounting procedures have long been used in the fields of economics and cognitive psychology, in recent years researchers in the medical field have begun to use these procedures to examine decision 
making concerning health and treatment options (e.g., Chapman et al., 2001; Chapman, Nelson, \& Hier, 1999; Critchfield \& Kollins, 2001; Hayman, Weeks, \& Mauch, 1996).

Delay discounting procedures may also have applications in the mental health field: They may be used to examine client preferences and decision making with regard to psychological treatment options. With this model, clients can compare two treatments that may differ in effectiveness (in terms of average rate of recovery) across differing amounts of time (number of requisite sessions of therapy). By systematically manipulating the effectiveness of two hypothetical treatments, values can be found that represent how large an increase in effectiveness is needed for a client to prefer to continue treatment for one session, two sessions, three sessions, and so forth. This method may also be used to place values of expected effectiveness on different durations of treatment.

The following studies were designed to examine expectations in a potential client population from which referrals are derived for a training clinic setting. Previous studies have indicated that, although the process by which successful courses of psychotherapy are completed is similar in the training clinic compared with other settings (Callahan, Swift, \& Hynan, 2006), the rate of change is slower and treatment may be less effective (in terms of reducing symptomatic distress) in this type of setting (Callahan \& Hynan, 2005; Kadera, Lambert, \& Andrews, 1996). Understanding expectations for treatment in this setting may be beneficial in explaining some of these differences. For example, clients in a training clinic setting may expect less from their therapist, because they may view the therapist as only a trainee, or clients in this setting may expect more from their therapist, requiring the therapist to prove himself or herself because of a lack of ascribed credibility. It is thus important to understand expectations in a referral base for a training clinic to better understand the process of change that occurs in this setting.

In the following studies, we used a delay discounting paradigm to examine expectations of treatment duration and treatment effectiveness within a population from which training clinic client referrals are generated. Study 1 compared the expected effectiveness of psychotherapy to the actual effectiveness of psychotherapy as found in the dose-effect literature, whereas Study 2 examined the possibility of altering such expectations.

\section{Study 1: Measuring Expectations}

In their meta-analysis, Howard, Kopta, Krause, and Orlinsky (1986) were interested in applying the dose-effect model from the medical field to psychotherapy by examining the relationship between the number of sessions of therapy received and the percentage of clients who improved. Outcomes from over 2,400 clients included in 15 different studies indicated that about $15 \%$ of clients improved prior to the first session, $50 \%$ were considered improved after 8 sessions, $75 \%$ were improved at 6 months of treatment (26 sessions), and $85 \%$ were improved at 1 year of treatment (52 sessions). On the basis of these data, the dose-effect relationship forms a negatively accelerated curve, indicating that, with a greater number of sessions, there is a greater likelihood of improvement; however, diminishing returns can be expected as the number of sessions, termed dosage by Howard et al. (p. 159), increases.
The introduction of the dose-effect relationship made by Howard et al.'s (1986) meta-analysis sparked much interest and further research in the area. Since the release of the seminal article, studies have explored the dose-effect relationship within diagnostic and symptom categories, in outpatient and other populations, across treatment orientation, with trainee clinicians, with a change criteria of clinical significance, and with session-by-session survival analyses (e.g., Barkham, Rees, Stiles, \& Shapiro, 1996; Callahan \& Hynan, 2005; Kadera et al., 1996; Kopta, Howard, Lowry, \& Beutler, 1994; Lueger, Lutz, \& Howard, 2000). Although somewhat different percentages of improved clients per session have been found across these studies, a negatively accelerated dose-effect relationship has been well replicated.

In attempting to summarize the results from the previously published literature on the dose-effect relationship, N. B. Hansen et al. (2002) examined the data from seven studies dating back to Howard et al.'s (1986) original meta-analysis. When taking into account differences in methodology and statistical analysis among the studies, N. B. Hansen et al. concluded that there is a general consensus that between 13 and 18 sessions of therapy are required for $50 \%$ of clients to improve (compared to 8 sessions reported by Howard et al.'s, 1986, meta-analysis). It was further concluded that clients who continue in treatment after the median number of sessions continue to show improvement, indicating that more treatment results in greater client response. Large scale studies (Lambert, Hansen, \& Finch, 2001; Wolgast, Lambert, \& Puschner, 2003) and studies conducted in training clinic settings (Callahan \& Hynan, 2005; Kadera et al., 1996) have found even more modest results for the effectiveness of psychotherapy than N. B. Hansen et al.'s and Howard et al.'s previous findings.

In summary, the literature on the dose-effect relationship of psychotherapy shows sharp contrasts between how many sessions are needed for treatment to be considered effective and how many sessions of treatment clients actually receive. This discrepancy appears to perhaps be greatest in the training clinic setting (Callahan \& Hynan, 2005; Kadera et al., 1996). Some have suggested that such discrepancies may be due to unmet outcome expectations (Clarkin \& Levy, 2003; Garfield, 1994; Wierzbicki \& Pekarik, 1993). Study 1 was designed to examine duration and effectiveness expectations. We used a delay discounting model to compare expectations with the actual effectiveness of treatment as indicated by the dose-effect literature, drawing participants from the primary referral base of a training clinic. When both expectations for effectiveness and expectations for duration are considered, expectations are thought to be similar to actual recovery as provided by the dose-effect literature (i.e., expectations form a positive, negatively accelerated curve), however, at a higher rate.

\section{Method}

\section{Participants}

Participants were 110 students enrolled at a Midwestern state university. The average participant age was 20.58 years, ranging from 18 to 43. Participants were primarily college students $(97.3 \%)$ and were relatively evenly distributed across grade levels. The majority of participants were female (71.8\%), single (93.6\%), and Caucasian (82.7\%). According to Myers and Bean's (1968) method for computing socioeconomic status (SES), $47 \%$ of par- 
ticipants were Level 3 SES (middle class), and 19\% were Level 4 SES (lower middle class). Only $2.7 \%$ of participants were receiving therapy at the time of participation.

\section{Measures}

Participants were asked to complete a delay discounting instrument with five different treatment scenarios. This instrument was developed on the basis of Madden, Begotka, Raif, and Kastern's (2003) instrument used to examine discounting rates for monetary values. The first scenario was designed to determine how effective (in terms of recovery rate, defined as percentage of clients to recover) a treatment that lasts 2 sessions must be in order to be seen as preferable to a treatment that lasts 1 session and is $15 \%$ effective (Howard et al.'s, 1986, recovery rate after 1 session). Participants were first given the choice between a treatment that lasted 1 session and exhibited a $15 \%$ recovery rate and a treatment that lasted 2 sessions and also showed a $15 \%$ recovery rate. After participants indicated the treatment they preferred, the effectiveness of the delayed treatment ( 2 sessions) was increased by $5 \%$ (to $20 \%$ ), and the participants were again asked to indicate a preference. After each subsequent choice, the delayed treatment's effectiveness was increased by $10 \%$ until it reached a maximum of $100 \%$ effectiveness, at which point the process was repeated in reverse order. This same process was replicated in the remaining four sections; however, instead of using a 2-session option, we used scenarios featuring a 4-session, 8-session, 15-session, and 26 -session delayed options. These lengths of treatment course were chosen to facilitate comparison with existing outcome literature. A sample of this instrument is given in the Appendix.

Delay discounting procedures have been used since the 1950s and have accumulated broad empirical support (Critchfield \& Kollins, 2001). Further, discounting rates have been shown to be stable across time (Chapman et al., 2001; Critchfield \& Kollins, 2001; Simpson \& Vuchinich, 2000) and sensitive to differences between groups expected to discount at different rates (Green, Fry, \& Myerson, 1994; Heil, Johnson, Higgins, \& Bickel, 2006; Madden, Petry, Badger, \& Bickel, 1997).

\section{Procedure}

After providing informed consent, participants completed an online survey that included demographic information and the delay discounting instrument. All participants were treated in accordance with APA's Ethical Principles of Psychologists and Code of Conduct (American Psychological Association, 2002). The study was approved and conducted in compliance with the university's internal review board.

\section{Results}

\section{Expected Recovery Rates}

The expected recovery rates in terms of percentage of clients expected to recover were calculated by averaging individual indifference points (the point at which the delayed treatment was first preferred) across participants. Participants, on average, preferred the 2-session treatment over the 1-session 15\%-effective treatment when it was $25.1 \%(S D=6.53)$ effective in terms of percentage of clients expected to recover. They preferred the 4-session treatment at $44.12 \%(S D=17.32)$, the 8 -session treatment at $61.62 \%(S D=$ $24.38)$, the 15 -session treatment at $72.36 \%(S D=24.37)$, and the 26 -session treatment at $77.39 \%(S D=25.00)$. A plot of these expected recovery rates with $95 \%$ confidence interval (CI) bars is found in Figure 1.

A one-way within-subjects analysis of variance was conducted to determine if participants' expected rates of recovery differed among 2, 4, 8, 15, and 26 sessions. Eleven participants were not included in this analysis because they did not complete all five scenarios. As expected, the omnibus effect was significant, $F(4$, $392)=271.09, p<.001, \eta^{2}=.73$, indicating that there was a difference in participants' expected recovery rates across scenarios. A trend analysis was further conducted to examine the difference across these conditions. Trend analysis indicated that both a linear trend, $F(1,98)=482.57, p<.001, \eta^{2}$ alerting $=.94$, and a quadratic trend, $F(1,98)=53.54, p<.001, \eta^{2}$ alerting $=.05$, were significant. These results indicate that, in general, as the number of sessions increases so does the expected rate of recovery (linear). However, a negatively accelerated curve instead of a straight linear line may be a better descriptor (as indicated by the significant quadratic trend) of the expectations.

\section{Comparing Expectations to the Dose-Effect Literature}

One-sample $t$ tests were conducted to first compare participant expectations to Howard et al.'s (1986) and N. B. Hansen et al.'s (2002) 50\% recovery rates. Whereas Howard et al. indicated that 8 sessions are required for $50 \%$ of clients to recover, participants in this sample expected $61.62 \%$ of clients to recovery by 8 sessions, thus demonstrating a significant difference, $t(107)=4.954$, $p<.001, d=0.48 ; M_{\text {diff }}=11.62,95 \%$ CI $=6.97-16.27$. Whereas N. B. Hansen et al. indicated that around 15 sessions are required for $50 \%$ of clients to recover, participants in this sample expected $72.36 \%$ of clients to recovery by 15 sessions, also indicating a significant difference, $t(107)=9.537, p<.001, d=0.92$; $M_{\text {diff }}=22.36,95 \% \mathrm{CI}=17.71-27.01$.

One-sample $t$ tests were also conducted to determine whether participant expectations at 2, 4, 8, 15, and 26 sessions were significantly different from the actual recovery rates for these sessions as described by Lambert et al. (2001). These comparisons indicated a significant difference at each of the session points and are reported in Table 1. Again, expectations were

Table 1

Comparison of Lambert et al.'s (2001) Observed Recovery Rates and Expected Recovery Rates

\begin{tabular}{rccccccc}
\hline \multirow{2}{*}{$\begin{array}{c}\text { Session } \\
\text { no. }\end{array}$} & $\begin{array}{c}\text { Lambert et al. } \\
(2001) \\
\text { observed }^{\text {a }}\end{array}$ & \multicolumn{3}{c}{ Sample expected } & & \\
\cline { 3 - 5 } & $N$ & $M$ rate & $S D$ & $t$ & $\begin{array}{c}\text { Effect } \\
\text { size } d\end{array}$ \\
\hline 2 & 7 & 102 & 25.10 & 6.53 & $27.98^{*}$ & 2.77 \\
4 & 16 & 108 & 44.12 & 17.37 & $16.82^{*}$ & 1.62 \\
8 & 30 & 108 & 61.62 & 24.38 & $13.48^{*}$ & 1.30 \\
15 & 44 & 108 & 72.36 & 24.37 & $12.10^{*}$ & 1.16 \\
26 & 56 & 109 & 77.39 & 25.00 & $8.93^{*}$ & 0.86 \\
\hline
\end{tabular}

a Values are approximations based on Figure 1 provided in Lambert et al. (2001) and personal communication with M. J. Lambert (March 1, 2007). ${ }^{*} p<.001$. 


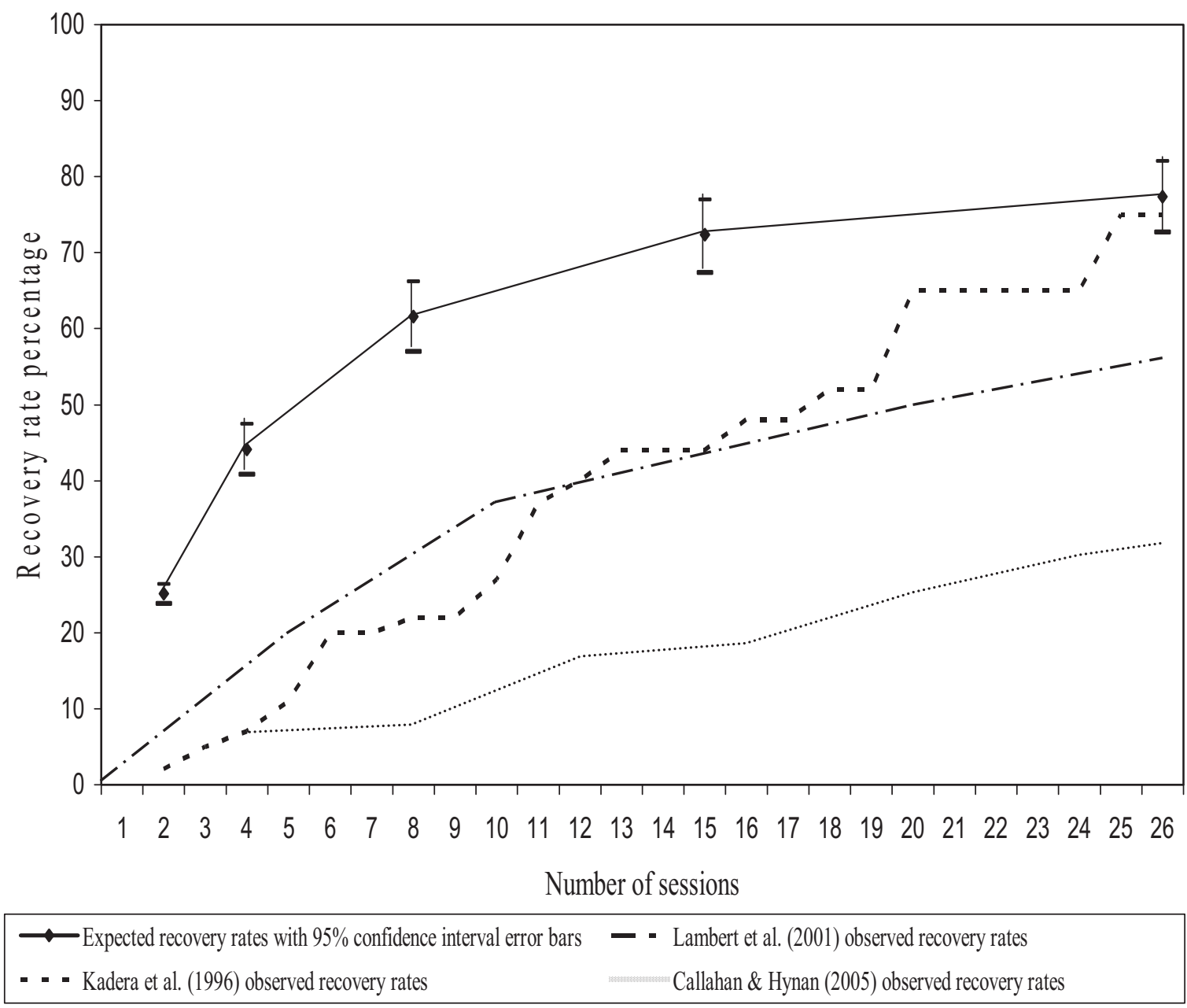

Figure 1. Expected recovery rates compared to observed dose-effect recovery rates. Data are adapted from Lambert et al. (2001, p. 164), Kadera et al. (1996, p. 143), and Callahan and Hynan (2005, p. 67).

significantly greater than the observed recovery rates for psychotherapy.

Further, one-sample $t$ tests were conducted to determine whether participant expectations differed from the recovery rates in a training clinic setting. Callahan and Hynan (2005) found 8 sessions to show an $8 \%$ recovery rate and found 26 sessions to show a $31 \%$ recovery rate. In contrast, participants expected 8 sessions to have a $61.62 \%$ recovery rate and expected 26 sessions to have a $77.39 \%$ recovery rate, again indicating a significant difference at both the 8-session point, $t(107)=22.86, p<.001, d=2.20$, and the 26 -session point, $t(108)=19.37, p<.001, d=1.86$. Kadera et al. (1996) found 4 sessions to show a $7 \%$ recovery rate and found 8 sessions to show a $22 \%$ recovery rate. Again, participants' expectations were significantly greater at both the 4-session point, $t(107)=22.21, p<.001, d=2.14$, and the 8-session point, $t(107)=16.89, p<.001, d=1.63$. In general, it was observed that participants' expectations for treatment recovery rates (percentage of clients expected to recover) were significantly higher than actual recovery rates across studies and settings. These recovery curve comparisons can be viewed in Figure 1.

\section{Study 2: Altering Expectations}

Study 1 indicated a discrepancy between expectations and the actual effectiveness of psychotherapy as reported by the doseeffect literature. Study 2 was designed to replicate the expectations found in the previous study and to examine the possibility of decreasing the discrepancy through client education.

When considering role expectations, previous studies have indicated that role induction or training prior to treatment can decrease the rate of dropout among clients (e.g., Orlinsky, Grawe, \& Parks, 1994; Scamardo, Bobele, \& Biever, 2004; Walitzer et al., 1999; Zwick \& Attkisson, 1985). It is thought that education in this area decreases the rate of dropout by shifting expectations to be more similar to what actually happens in psychotherapy (Reis \& Brown, 2006). It would follow that education in the area of treatment effectiveness may also shift expectations to be more similar to the actual effectiveness of psychotherapy, thus further decreasing treatment dropout.

This hypothesis was studied by Reis and Brown (2006), who examined whether dropout could be decreased by discussing treat- 
ment duration with clients prior to treatment. Their study indicated that such a discussion had no effects. However, Reis and Brown's method of education (the therapist asking the client how many sessions they expected to attend and encouraging more realistic expectations if the minimum estimate was not given) and the minimum qualifications that they considered to be realistic (three or more sessions as acceptable expectations) may be limitations that led to these negligible results. Reis and Brown themselves questioned the basis for their estimate procedure (p. 315). It is thought that education involving the effectiveness of psychotherapy as given by the dose-effect literature may show more positive results in altering effectiveness expectations.

\section{Method}

\section{Participants}

Participants in Study 2 were 307 students enrolled at the same Midwestern state university as in Study 1. The average participant age was 19.92 years, ranging from 18 to 42 . Participants were primarily college students $(96.7 \%)$. The majority of participants were female $(68.4 \%)$, single $(96.4 \%)$, and Caucasian $(84.5 \%)$. According to Myers and Bean's (1968) method for computing SES, $62.4 \%$ of participants were Level 3 SES (middle class), and $25.2 \%$ were Level 4 SES (lower middle class). In this study, $6.0 \%$ of participants were receiving therapy from a mental health professional at the time of participation.

\section{Measures}

Delay discounting instrument. Participants were asked to complete the same delay discounting instrument with the five different treatment scenarios as discussed in Study 1.

Measure of duration expectations. As a measure of treatment duration expectations, participants were asked to imagine that they were experiencing distress and were thinking about seeking treatment. They were then asked how many sessions they expected to attend in order to recover.

\section{Procedure}

Participants were randomly assigned to one of two groups, a duration education group $(N=155)$ and a control group $(N=$ $152)$. No differences were seen between groups on any of the demographic variables. Participants in both groups completed an online survey that included demographic information, the delay discounting instrument, and the measure of duration expectations. Those in the duration education group were also provided with the following sentence as part of the instructional set for the measure of duration expectations: "The research findings indicate that on average it takes approximately 15 therapy sessions for $50 \%$ of clients to recover." As in the first study, all participants were treated in accordance with APA's Ethical Principles of Psychologists and Code of Conduct (American Psychological Association, 2002). This study was conducted in compliance with the university's internal review board.

\section{Results}

\section{Replicating the Expected Recovery Rates}

The expected recovery rates were calculated by averaging individual indifference points (the point at which the delayed treatment was preferred) across participants in the same manner as in Study 1. Participants, on average, preferred the 2-session treatment over the 1 -session $15 \%$-effective treatment when it was $24.43 \%$ ( $S D=$ 7.99) effective. They preferred the 4 -session treatment at $44.41 \%$ $(S D=16.13)$, the 8 -session treatment at $59.69 \%(S D=22.81)$, the 15 -session treatment at $71.31 \%(S D=23.75)$, and the 26 -session treatment at $76.88 \%(S D=23.81)$. One-sample $t$ tests comparing Study 2 expected recovery rates with Study 1 expected rates indicated no significant differences $(p>.05)$ at any of the session points.

\section{The Effect of Education}

An independent samples $t$ test was conducted comparing participants who received the duration education with participants in the control group who did not receive the education. Two participants were excluded from this analysis because they provided scores that were greater than 3 standard deviations from the means (1 participant per group). A significant difference was seen between the groups, $t(295)=9.44, p<.001, d=1.10$, thus indicating that participants who received the duration education expected a longer treatment duration $(M=17.12, S D=8.52)$ as compared with participants who did not receive the duration education $\left(M=8.23, S D=7.67 ; M_{\text {diff }}=8.89,95 \% \mathrm{CI}=7.03\right.$ 10.74). A post hoc one-sample $t$ test indicated that participants in the education group, on average, expected a treatment duration that was greater than the education duration (15 sessions for $50 \%$ recovery rate) that they were given, $t(149)=3.04, p<.001, d=$ 0.25 .

\section{Discussion}

The dose-effect literature generally indicates that it takes somewhere between 13 and 18 (N. B. Hansen et al., 2002) sessions of therapy for $50 \%$ of clients to recover. However, the literature also indicates that the average number of sessions that a client attends is somewhere between 3 and 5 (Garfield, 1994; N. B. Hansen et al., 2002). Thus, a large number of clients are discontinuing treatment before they have actually recovered. A number of researchers examining this phenomenon of premature termination have noted that unmet client expectations may play a large role in clients' reasons for discontinuation of treatment (Garfield, 1994). Much of the literature exploring the effect of unmet expectations on early termination has focused on unmet role expectations (e.g., Nock \& Kazdin, 2001; Reis \& Brown, 1999; Walitzer et al., 1999), whereas little attention has been given to unmet outcome expectations. In Study 1, we used a training clinic referral base to examine participants' expectations of treatment duration and effectiveness by using a delay discounting model, whereas in Study 2, we (a) replicated the results found in Study 1 and (b) examined whether unrealistic expectations may be altered to become more similar to what actually occurs in psychotherapy.

With a delay discounting method, we found that participants expected a 2 -session treatment to have a $25 \%$ recovery rate (i.e., they expected that $25 \%$ of clients would recover by Session 2), 4 sessions to have a $44 \%$ recovery rate, 8 sessions a $62 \%$ recovery rate, 15 sessions to have a $72 \%$ recovery rate, and 26 sessions to have a $77 \%$ recovery rate. Nearly identical expected recovery rates were replicated with a larger sample in Study 2. We found that 
these expectations for effectiveness followed a negatively accelerated positive curve across sessions, demonstrating expectations for big gains in rate of recovery after the early sessions, followed by continual, but diminishing, gains as treatment continued in length. This negatively accelerated positive curve in expectations is the same pattern that is observed in the dose-effect literature. Further, comparing these expectations to the dose-effect literature indicates that expectations for therapy are greater than the actual rate of improvement demonstrated by psychotherapy.

The discrepancy between expectations and the actual effectiveness of psychotherapy may play a role in the large number of clients discontinuing treatment before they have actually recovered. One explanation is that clients may enter therapy expecting to recover after only a relatively small number of sessions, and when they do not recover as quickly as expected, they drop out of treatment feeling unsatisfied. A second explanation tying premature termination to unmet expectations pertains to the phase model (Howard, Lueger, Maling, \& Martinovich, 1993), which suggests that clients often make early gains in remoralization (subjective well-being). It follows that clients may experience this early improvement and assume that they are well on their way to recovery and no longer in need of professional assistance, because the improvement is in line with their expectations.

On the basis of these results, the question that follows is, What can be done to improve treatment outcome and lower the number of clients who terminate treatment prematurely? The literature indicates that educating clients at the start of treatment in the area of role expectations can improve client satisfaction, lengthen treatment duration, and improve overall treatment outcome (e.g., Orlinsky, Grawe, \& Parks, 1994; Reis \& Brown, 2006; Scamardo et al., 2004; Walitzer et al., 1999; Zwick \& Attkisson, 1985). As a result, it has been suggested that clinicians use some method of role induction, such as video presentations, distribution of pamphlets describing therapy, and therapist-client discussions about preexisting preferences and expectations. It has been suggested that these educational sessions occur prior to treatment as part of a treatment preparation session (Reis \& Brown, 2006); however, discussions of the process of treatment can and often do occur throughout treatment whenever the client's unrealistic role expectations are thought to be causing a problem.

Along the same lines of client induction, Study 2 found that expectations for treatment duration can also be altered through education. Specifically, participants who were advised of the actual effectiveness of psychotherapy, as indicated by the doseeffect literature, showed expectations for treatment duration (17 sessions) that nearly doubled those of participants who received no education ( 8 sessions). These more realistic duration expectations may lead to longer treatment durations and fewer treatment dropouts (Mueller \& Pekarik, 2000; Pekarik \& Wierzbicki, 1986); however, whether such education effects persist over time in shifting expectations and whether the altering of expectations produces improved treatment outcomes are worth examining in future research.

Similar to role induction, a number of recommendations can be made concerning the type and timing of treatment effectiveness and duration education. The education used in this study was computer based and consisted of only one sentence describing research results concerning the effectiveness of psychotherapy, thereby suggesting that brief educational interventions (such as video presentations or pamphlets describing therapy) can be highly efficient and cost effective. However, a more detailed therapistclient discussion may also be beneficial and could include a description of (a) the dose-effect model and how many sessions it typically takes for the average client to improve (50\% at about 8 sessions) or recover (50\% at 13-18 sessions), (b) the phase model and how many sessions it may take before a client may expect to see improvements in well-being compared to symptom reduction or overall life functioning, (c) the erroneous high expectations that many clients enter therapy with, and (d) the problem of premature termination and how it relates to unmet expectations. We also suggest that outcome education occur at the start of treatment or during an initial visit as a preparation for therapy; however, a discussion of treatment outcome may also be beneficial whenever it is thought that unrealistic expectations may lead to early treatment dropout.

In this study, participants were asked to choose between treatments that differed in length and level of effectiveness. With these questions, level of effectiveness was defined as rate of recovery (i.e., the percentage of clients who recovered by the end of a given number of sessions). This definition of effectiveness was used to facilitate comparison to the dose-effect literature, which also uses rate of recovery. However, rate of recovery may not be the most meaningful definition of effectiveness for the individual participant. Instead, a more meaningful definition may be level of symptom improvement (e.g., "Would you prefer a treatment that lasts 1 session and alleviates $15 \%$ of your symptoms or one that last 15 sessions and alleviates $100 \%$ of your symptoms?"). Current methods, including the OQ-45.2, can predict clients' trajectories of improvement across sessions on the basis of their levels of distress at the beginning of treatment (Lambert et al., 2001). However, explaining trajectories of improvement to clients in terms of percentage of symptom alleviation may be difficult because different clients are likely to have different opinions about the definition of symptom alleviation (symptom reduction vs. improvements in well-being etc.). For the research purposes of this study, it was important to ask participants about their expectations in terms of recovery, as compared to expectations in terms of symptom alleviation, in order to facilitate comparison to the dose-effect literature. However, in a practice setting, it would be important to discuss expectations in both areas.

It should be noted that the participants in this study were undergraduate students who were largely homogeneous in their racial identity. This sample represents a referral base for a training clinic. It is of interest to understand the expectations of this population; however, comparisons of this population to actual outcomes in clients may explain some of the differences that were seen. This, as well as the issue of racial generalizability, may require further exploration with regard to their effect on treatment outcome expectations in future studies.

\section{References}

American Psychological Association. (2002). Ethical principles of psychologists and code of conduct. Washington, DC: Author.

Barkham, M., Rees, A., Stiles, W. B., \& Shapiro, D. A. (1996). Doseeffect relations in time-limited psychotherapy for depression. Journal of Consulting and Clinical Psychology, 64, 927-935.

Callahan, J. L., \& Hynan, M. T. (2005). Models of psychotherapy outcome: 
Are they applicable in training clinics? Psychological Services, 2, 6569.

Callahan, J. L., Swift, J. K., \& Hynan, M. T. (2006). Test of the phase model of psychotherapy in a training clinic. Psychological Services, 3 , $129-136$

Chapman, G. B., Brewer, N. T., Coups, E. J., Brownlee, S., Leventhal, H., \& Levanthal, E. A. (2001). Value for the future and preventive health behavior. Journal of Experimental Psychology: Applied, 7, 235-250.

Chapman, G. B., Nelson, R., \& Hier, D. B. (1999). Familiarity and time preferences: Decision making about treatments for migraine headaches and Crohn's disease. Journal of Experimental Psychology: Applied, 5, $17-34$.

Clarkin, J. F., \& Levy, K. N. (2003). Influence of client variables on psychotherapy. In M. Lambert (Ed.), Handbook of psychotherapy and behavior change (5th ed., pp. 194-226). New York: Wiley.

Critchfield, T. S., \& Kollins, S. H. (2001). Temporal discounting: Basic research and the analysis of socially important behavior. Journal of Applied Behavior Analysis, 34, 101-121.

Dew, S. E., \& Bickman, L. (2005). Client expectancies about therapy. Mental Health Services Research, 7, 21-33.

Garcia, J. A., \& Weisz, J. R. (2002). When youth mental health care stops: Therapeutic relationship problems and other reasons for ending youth outpatient treatment. Journal of Consulting and Clinical Psychology, 70, 439-443.

Garfield, S. L. (1994). Research on client variables in psychotherapy. In A. E. Bergin \& S. L. Garfield (Eds.), Handbook of psychotherapy and behavior change (4th ed., pp. 190-228). New York: Wiley.)

Green, L., Fry, A. F., \& Myerson, J. (1994). Discounting of delayed rewards: A life-span comparison. Psychological Science, 5, 33-36.

Hansen, A. M., Hoogduin, C. A., Schaap, C., \& de Haan, E. (1992). Do drop-outs differ from successfully treated obsessive-compulsives? Behaviour Research and Therapy, 30, 547-550.

Hansen, N. B., Lambert, M. J., \& Forman, E. M. (2002). The psychotherapy dose-response effect and its implications for treatment delivery services. Clinical Psychology: Science and Practice, 9, 329-343.

Hardin, S. I., Subich, L. M., \& Holvey, J. M. (1988). Expectancies for counseling in relation to premature termination. Journal of Counseling Psychology, 35, 37-40.

Hayman, J., Weeks, J., \& Mauch, P. (1996). Economic analyses in health care: An introduction to the methodology with an emphasis on radiation therapy. International Journal of Radiation Oncology, Biology, Physics, $35,827-841$.

Heil, S. H., Johnson, M. W., Higgins, S. T., \& Bickel, W. K. (2006). Delay discounting in currently using and currently abstinent cocaine-dependent outpatients and non-drug-using matched controls. Addictive Behaviors, 31, 1290-1294.

Howard, K. I., Kopta, S. M., Krause, M. S., \& Orlinsky, D. E. (1986). The dose-effect relationship in psychotherapy. American Psychologist, 41, $159-164$

Howard, K. I., Lueger, R. J., Maling, M. S., \& Martinovich, Z. (1993). A phase model of psychotherapy outcome: Causal mediation of change. Journal of Consulting and Clinical Psychology, 61, 678-685.

Kadera, S. W., Lambert, M. J., \& Andrews, A. A. (1996). How much therapy is really enough? A session-by-session analysis of the psychotherapy dose-effect relationship. Journal of Psychotherapy Practice \& Research, 5, 132-151.
Kopta, S. M., Howard, K. I., Lowry, J. L., \& Beutler, L. E. (1994). Patterns of symptomatic recovery in psychotherapy. Journal of Consulting and Clinical Psychology, 62, 1009-1016.

Lambert, M. J., Hansen, N. B., \& Finch, A. E. (2001). Patient-focused research: Using patient outcome data to enhance treatment effects. Journal of Consulting and Clinical Psychology, 69, 159-172.

Lueger, R. J., Lutz, W., \& Howard, K. I. (2000). The prediction and observed course of psychotherapy for anxiety and mood disorders. Journal of Nervous and Mental Disease, 188, 127-134.

Madden, G. J., Begotka, A. M., Raif, B. R., \& Kastern, L. L. (2003). Delay discounting of real and hypothetical rewards. Experimental and Clinical Psychopharmacology, 11, 139-145.

Madden, G. J., Petry, N. M., Badger, G. J., \& Bickel, W. K. (1997). Impulsive and self-control choices in opioid-dependent patients and non-drug-using control participants: Drug and monetary rewards. Experimental and Clinical Psychopharmacology, 5, 256-262.

Mueller, M., \& Pekarik, G. (2000). Treatment duration prediction: Client accuracy and its relationship to dropout, outcome, and satisfaction. Psychotherapy: Theory, Research, Practice, Training, 37, 117-123.

Myers, J. K., \& Bean, L. L. (1968). A decade later: A follow up of social class and mental illness. New York: Wiley.

Nock, M. K., \& Kazdin, A. E. (2001). Parent expectancies for child therapy: Assessment and relation to participation in treatment. Journal of Child and Family Studies, 10, 155-180.

Orlinsky, D. E., Grawe, K., \& Parks, B. K. (1994). Process and outcome in psychotherapy: Noch einmal. In A. E. Bergin \& S. L. Garfield (Eds.), Handbook of psychotherapy and behavior change (4th ed., pp. 270376). New York: Wiley.

Pekarik, G. (1991). Relationship of expected and actual treatment duration for adult and child clients. Journal of Clinical Child Psychology, 20, 121-125.

Pekarik, G., \& Wierzbicki, M. (1986). The relationship between clients' expected and actual treatment duration. Psychotherapy: Theory, Research, Practice, Training, 23, 532-534.

Reis, B. F., \& Brown, L. G. (1999). Reducing psychotherapy dropouts: Maximizing perspective convergence in the psychotherapy dyad. Psychotherapy: Theory, Research, Practice, Training, 36, 123-136.

Reis, B. F., \& Brown, L. G. (2006). Preventing therapy dropout in the real world: The clinical utility of videotape preparation and client estimate of treatment duration. Professional Psychology: Research and Practice, $37,311-316$

Scamardo, M., Bobele, M., \& Biever, J. L. (2004). A new perspective on client dropouts. Journal of Systemic Therapies, 23(2), 27-38.

Simpson, C. A., \& Vuchinich, R. E. (2000). Reliability of a measure of temporal discounting. Psychological Record, 50, 3-16.

Walitzer, K. S., Dermen, K. H., \& Conners, G. J. (1999). Strategies for preparing clients for treatment: A review. Behavior Modification, 23, 129-151.

Wierzbicki, M., \& Pekarik, G. (1993). A meta-analysis of psychotherapy dropout. Professional Psychology: Research and Practice, 24, 190-195.

Wolgast, B. M., Lambert, M. J., \& Puschner, B. (2003). The dose-response relationship at a college counseling center: Implications for setting session limits. Journal of College Student Psychotherapy, 18, 15-29.

Zwick, R., \& Attkisson, C. C. (1985). Effectiveness of a client pretherapy orientation videotape. Journal of Counseling Psychology, 32, 514-524. 


\section{Appendix}

\section{Sample Delay Discounting Instrument With Treatment Options}

You have the option of choosing a treatment that is $15 \%$ effective after 1 therapy session (15\% of clients that receive this treatment recover after 1 session of therapy) and a treatment that is $15 \%$ effective after 15 therapy sessions $(15 \%$ of clients that receive this treatment recover after 15 sessions of therapy). These therapy sessions are each 1 hour long and are provided once per week. Which would you prefer?

Would you prefer the treatment that is $15 \%$ effective after 1 session or the treatment that is $15 \%$ effective after 15 sessions?

$15 \%$ effective after 1 session

$15 \%$ effective after 15 sessions

Would you prefer the treatment that is $15 \%$ effective after 1 session or the treatment that is $20 \%$ effective after 15 sessions?

$15 \%$ effective after 1 session

$20 \%$ effective after 15 sessions
Would you prefer the treatment that is $15 \%$ effective after 1 session or the treatment that is $30 \%$ effective after 15 sessions?

$15 \%$ effective after 1 session

$30 \%$ effective after 15 sessions

Questions were spaced online so that only one question could be seen at a time. Questions continued until the delayed treatment option was $100 \%$ effective and then were repeated in reverse order. The average point at which participants preferred the delayed treatment option was taken as the participant indifference point or expectation for that treatment option.

Received July 31, 2007

Revision received November 20, 2007

Accepted January 8, 2008

\section{New Editors Appointed, 2010-2015}

The Publications and Communications Board of the American Psychological Association announces the appointment of 4 new editors for 6-year terms beginning in 2010. As of January 1, 2009, manuscripts should be directed as follows:

- Psychological Assessment (http://www.apa.org/journals/pas), Cecil R. Reynolds, PhD, Department of Educational Psychology, Texas A\&M University, 704 Harrington Education Center, College Station, TX 77843.

- Journal of Family Psychology (http://www.apa.org/journals/fam), Nadine Kaslow, PhD, Department of Psychiatry and Behavioral Sciences, Grady Health System, 80 Jesse Hill Jr. Drive, SE, Atlanta, GA 30303.

- Journal of Experimental Psychology: Animal Behavior Processes (http://www.apa.org/ journals/xan), Anthony Dickinson, PhD, Department of Experimental Psychology, University of Cambridge, Downing Street, Cambridge CB2 3EB, United Kingdom

- Journal of Personality and Social Psychology: Personality Processes and Individual Differences (http://www.apa.org/journals/psp), Laura A. King, PhD, Department of Psychological Sciences, University of Missouri, McAlester Hall, Columbia, MO 65211.

Electronic manuscript submission: As of January 1, 2009, manuscripts should be submitted electronically via the journal's Manuscript Submission Portal (see the website listed above with each journal title).

Manuscript submission patterns make the precise date of completion of the 2009 volumes uncertain. Current editors, Milton E. Strauss, PhD, Anne E. Kazak, PhD, Nicholas Mackintosh, $\mathrm{PhD}$, and Charles $\mathrm{S}$. Carver, $\mathrm{PhD}$, will receive and consider manuscripts through December 31, 2008. Should 2009 volumes be completed before that date, manuscripts will be redirected to the new editors for consideration in 2010 volumes. 